\title{
ESTUDO DE DIFERENTES TRATAMENTOS DO ÓLEO DE PALMA BRUTO PARA A PRODUÇÃO DE BIODIESEL PELA ROTA ETÍLICA
}

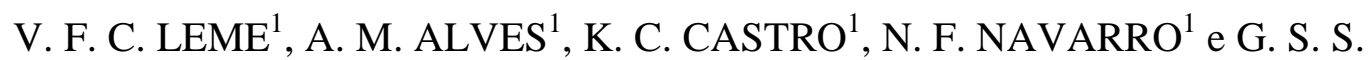 \\ ANDRADE $^{1}$ \\ ${ }^{1}$ Universidade Federal de Alfenas, Instituto de Ciência e Tecnologia \\ E-mail para contato: vitoria.leme@ hotmail.com
}

\begin{abstract}
RESUMO - A produção de biodiesel convencional utiliza a catálise básica homogênea e emprega óleo vegetal refinado e metanol. Com objetivo de utilizar matérias-primas de baixo custo (óleo vegetal bruto) e substituir o metanol (tóxico) pelo etanol (renovável) o presente trabalho investigou duas formas simples e de baixo custo para o tratamento do óleo de palma bruto: a centrifugação, para retirada de sólidos em suspensão e a degomagem para remoção de fosfatídeos e ceras. A técnica de degomagem é amplamente aplicada na área industrial para refino de óleo bruto em virtude do baixo custo. Ambos os tratamentos visaram promover a melhora dos aspectos físico-químicos do óleo, facilitando assim a reação de transesterificação pela rota etílica e catálise básica homogênea. Após os tratamentos verificou-se que não houve mudança significativa nas análises dos índices de acidez e peróxido entre o óleo bruto e os óleos tratados. Entretanto, as amostras de biodiesel obtidas a partir desses óleos apresentaram baixa viscosidade e redução nos índices acidez e peróxido. Esses resultados demonstram que é possível produzir biodiesel de boa qualidade pela catálise química convencional empregando óleo de palma bruto e etanol, sem a necessidade de nenhum tipo de tratamento prévio e dispendioso.
\end{abstract}

\section{INTRODUÇÃO}

Biodiesel é definido como um combustível renovável constituído por ésteres monoalquílicos de ácidos graxos de cadeia longa derivados de óleos vegetais ou gorduras animais. Trata-se de um combustível ambientalmente amigável visto que a sua utilização em motores diesel convencionais resulta em uma redução substancial na emissão de hidrocarbonetos não queimados, monóxido de carbono e partículas (Sajjadi et al., 2016). Pode ser produzido a partir de diferentes matérias-primas tais como óleos brutos e refinados e gorduras residuais utilizando uma grande variedade de catalisadores. Em virtude de a matériaprima lipídica representar cerca de $80 \%$ dos custos globais de produção de biodiesel, além da questão alimentos versus combustível, a investigação sobre óleos não comestíveis ou resíduos vem sendo intensificada globalmente (Kurnia et al.,2016). Além disso, a substituição do metanol (tóxico) pelo etanol (renovável) na reação de transesterificação torna o processo ambientalmente favorável. 
Apesar da catálise básica homogênea apresentar algumas desvantagens como possibilidade de saponificação, dificuldade de reutilização do catalisador e geração de elevadas quantidades de águas residuárias, atualmente os catalisadores básicos homogêneos tais como $\mathrm{KOH}, \mathrm{NaOH}$, metóxido ou etóxido de sódio são os mais empregados industrialmente devido à sua elevada atividade catalítica e ampla disponibilidade. No entanto, não são adequados em processos que utilizam matérias-primas com elevados teores em água e ácidos graxos livres. Nesse aspecto o presente trabalho tem como objetivo avaliar dois tratamentos simples e de baixo custo (centrifugação e degomagem) no óleo de palma bruto para que possa ser empregado de forma eficiente na síntese de biodiesel pela rota etílica empregando catálise básica homogênea convencional. Espera-se que com a retirada de ceras e fosfatídeos através da separação simples e da precipitação dos fosfatídeos, haja melhora nos aspectos físico-químicos do óleo, permitindo a obtenção de elevados rendimentos de transesterficação.

\section{MATERIAIS E MÉTODOS}

\subsection{Materiais}

As matérias-primas utilizadas nas reações de transesterificação foram: óleo de palma bruto e refinado obtido comercialmente (Agropalma-PA), álcool etílico anidro (Synth) e hidróxido de potássio $(\mathrm{KOH})$ em pellets (Synth). Os reagentes empregados nas análises de acidez e peróxido foram de grau analítico.

\subsection{Caracterização do óleo e do biodiesel}

Todas as análises físico-químicas (índice de acidez e de peróxido) foram determinadas pela metodologia oficial descrita pelo Instituto Adolfo Lutz (Instituto Adolfo Lutz, 2008) e realizadas em triplicatas. Índice de Peróxido (IP): Em um erlenmeyer de $125 \mathrm{~mL}$ foram colocados $1 \mathrm{~g}$ da amostra. Em seguida, adicionou-se $6 \mathrm{~mL}$ de solução ácido acético e clorofórmio 3:2 (v/v) e 0,1 mL de solução saturada de iodeto de potássio. Agitou-se por cerca de 2 minutos. Em seguida, adicionou-se $40 \mathrm{~mL}$ de água destilada e $0,1 \mathrm{~mL}$ de solução de amido a $1 \%$. Procedeu-se à titulação com solução de tiossulfato de sódio a $0,01 \mathrm{M}$ até a mistura ficar transparente. Índice de Acidez (IA): Em um erlenmeyer de $125 \mathrm{~mL}$ colocou-se 2 $\mathrm{g}$ da amostra. Adicionou-se $30 \mathrm{~mL}$ de solução éter etílico e álcool etílico 1:1 (v/v). Agitou-se até a completa diluição da amostra. Foram adicionados ao sistema 3 gotas do indicador fenolftaleína. Procedeu-se a titulação com solução de $\mathrm{KOH}(0,1 \mathrm{~N})$ até o surgimento da coloração rósea, estável por 30 segundos.

As análises de viscosidade, densidade e umidade foram determinadas conforme norma da ANP (ANP, 2014) para biodiesel. Viscosidade: A viscosidade dinâmica foi determinada por viscosímetro Brookfield modelo LVDV-I Prime (Brookfield Engineering Laboratories, Estados Unidos), à temperatura de $40^{\circ} \mathrm{C}$. A viscosidade cinemática foi calculada pela divisão simples entre a viscosidade dinâmica e a densidade. Densidade: A densidade foi determinada pela técnica de picnometria a temperatura de $20^{\circ} \mathrm{C}$. Mediu-se a massa do picnômetro limpo e vazio. Completou-o com água para a calibração e mediu-se a massa. Em seguida, adicionouse a amostra e mediu-se a massa. De posse das massas da amostra e do volume do picnômetro, foi possível obter a densidade específica na temperatura estabelecida. Umidade: 
Secou-se o cadinho por 1 hora em estufa a $105^{\circ} \mathrm{C}$ e logo após colocou-o no dessecador com sílica para resfriamento total. Mediu-se a massa do cadinho vazio e então adicionou-se $1,00 \mathrm{~g}$ da amostra. $\mathrm{O}$ sistema foi colocado em estufa a $105^{\circ} \mathrm{C}$ e após 1 hora foi para o dessecador até resfriamento à temperatura ambiente. Realizou-se a pesagem. Repetiu-se o procedimento até massa constante. Espectroscopia de infravermelho por Transformada de Fourier (FTIR): A análise de espectroscopia no infravermelho das amostras foi realizada no espectrômetro Agilent Technlogies modelo Cary 630. As amostras foram inseridas diretamente no equipamento e as análises foram conduzidas na faixa de comprimento de onda de 4000 a 600 $\mathrm{cm}^{-1}$.

\subsection{Tratamento do óleo bruto}

Os óleos foram submetidos a dois tratamentos, centrifugação e degomagem. Centrifugação: Para separar os sólidos em suspensão, o óleo de palma bruto foi centrifugado a 3500 rpm por 15 minutos em centrífuga SL-700 (Solab). Degomagem: Para retirar ceras e gomas, foi adicionado $3 \% \mathrm{v} / \mathrm{v}$ de água a $70^{\circ} \mathrm{C}$ ao óleo de palma centrifugado sob agitação mecânica $(350 \mathrm{rpm})$. O sistema foi mantido sob agitação mecânica por 20 minutos. Em seguida, centrifugou-se (centrífuga SL-700 Solab) a mistura novamente (3500 rpm, 15 minutos) para separação da fase aquosa.

\subsection{Reação de transesterificação e purificação dos ésteres etílicos}

O meio reacional foi composto por óleo de palma (bruto, centrifugado, degomado e refinado) e etanol anidro em uma razão molar de 1:9 (óleo:álcool) com adição de $2 \% \mathrm{~m} / \mathrm{m}$ (em relação à massa de óleo) de catalisador homogêneo $\mathrm{KOH}$. Em quatro balões de fundo redondo de $250 \mathrm{ml} \mathrm{o} \mathrm{KOH}$ foi adicionado ao etanol e mantido sob agitação magnética até completa dissolução. Logo em seguida, o óleo de palma (bruto, centrifugado, degomado e refinado) previamente aquecido a $45^{\circ} \mathrm{C}$ foi adicionado a solução álcool/catalisador e mantidos sob agitação magnética e aquecimento a $45^{\circ} \mathrm{C}$ em banho de glicerina por 30 minutos. Os experimentos foram realizados em duplicata. Decorrido esse período, o produto obtido foi colocado em um funil de separação para separar as fases contendo glicerol e os ésteres etílicos. O glicerol foi descartado. Para a purificação dos ésteres etílicos, ainda no funil de separação foi adicionada uma quantidade de água (um terço do volume do líquido obtido). A mistura foi agitada levemente e deixada em repouso por $24 \mathrm{~h}$ para separação das fases. A fase inferior (aquosa) foi descartada. Esse procedimento foi realizado em triplicata. O etanol residual contido na fase superior (ésteres etílicos) foi evaporado em rotaevaporador (15 min, $90{ }^{\circ} \mathrm{C}$ ). Por fim, adicionou-se sulfato de sódio anidro ao biodiesel obtido para retirada da água residual.

\section{RESULTADOS E DISCUSSÕES}

\subsection{Caracterização do óleo de palma}

A fim de avaliar o efeito dos tratamentos realizados sobre a matéria-prima lipídica bruta, a mesma foi caracterizada antes e após os tratamentos. Para fins de controle, as mesmas análises foram realizadas também no óleo de palma refinado (comercial). Os resultados obtidos encontram-se na Tabela 1. 
A análise físico-química da matéria prima é uma etapa muito importante uma vez que estas características podem influenciar no tipo de processo a ser utilizado e na qualidade final do biocombustível.

Tabela 1 - Propriedades físico-químicas do óleo de palma bruto, centrifugado, degomado e refinado

\begin{tabular}{|c|c|c|c|c|}
\hline Análises & $\begin{array}{c}\text { Óleo } \\
\text { Bruto }\end{array}$ & $\begin{array}{c}\text { Óleo } \\
\text { Centrifugado }\end{array}$ & $\begin{array}{c}\text { Óleo } \\
\text { Degomado }\end{array}$ & $\begin{array}{c}\text { Óleo } \\
\text { Refinado }\end{array}$ \\
\hline \hline Índice de Acidez $(\mathrm{mg} \mathrm{KOH} / \mathrm{g}$ óleo) & $10,28 \pm 0,17$ & $10,16 \pm 0,07$ & $10,37 \pm 0,10$ & $1,00 \pm 0,07$ \\
\hline Índice de Peróxido $(\mathrm{meq} / \mathrm{kg}$ óleo) & $21,50 \pm 0,7$ & $18,00 \pm 0,00$ & $25,50 \pm 0,71$ & $16,00 \pm 4,24$ \\
\hline Densidade $\left(\mathrm{kg} / \mathrm{m}^{3}\right)$ & $882,36 \pm 3,05$ & $888,76 \pm 0,93$ & $898,96 \pm 1,55$ & $886,40 \pm 0,65$ \\
\hline Viscosidade Dinâmica $(\mathrm{cP})$ & $45,09 \pm 0,07$ & $34,10 \pm 0,20$ & $33,15 \pm 0,07$ & $33,40 \pm 0,10$ \\
\hline Viscosidade Cinemática $\left(\mathrm{mm}^{2} / \mathrm{s}\right)$ & $55,59 \pm 0,08$ & $38,31 \pm 0,24$ & $36,88 \pm 0,08$ & $37,68 \pm 0,16$ \\
\hline Umidade $(\%)$ & $0,05 \pm 0,12$ & $0,01 \pm 0,13$ & $0,13 \pm 0,06$ & 0,00 \\
\hline
\end{tabular}

Conforme descrito na Tabela 1 , os tratamentos realizados não conseguiram reduzir a acidez no óleo bruto que ficou em torno de $10 \mathrm{mgKOH} / \mathrm{g}$ óleo, dez vezes acima do obtido para o óleo de palma refinado. Isso indica que o processo de degomagem não é capaz de remover os ácidos graxos livres, havendo a necessidade de adicionar um processo de neutralização com um reagente básico. Altos índices de acidez e água podem dificultar ou mesmo inviabilizar o processo de produção de biodiesel via catálise homogênea em meio alcalino favorecendo a reação paralela à reação de transesterificação que é a saponificação. No entanto, segundo a Resolução $\mathrm{n}^{\circ} 184$ da ANVISA (2005) (Agência de Vigilância Sanitária) esse valor está dentro do limite estabelecido que é de $10 \mathrm{mgKOH} / \mathrm{g}$ óleo.

Com relação ao índice de peróxido, houve uma pequena redução após a centrifugação do óleo bruto, que passou de 21,5 para $18 \mathrm{meq} / \mathrm{kg}$ óleo. Entretanto, após a etapa de purificação por degomagem, o IP aumentou para $25,5 \mathrm{meq} / \mathrm{kg}$ óleo, indicando que o tratamento foi prejudicial a amostra bruta. Além disso, o óleo refinado também apresentou elevado IP de $16 \mathrm{meq} / \mathrm{kg}$ óleo, provavelmente pelo elevado tempo de armazenamento em condições não ideais, o que contribuiu para o aumento da oxidação do óleo. Esses valores encontram-se acima do estabelecido pela Resolução $\mathrm{n}^{\circ} 184$ da ANVISA (2005), que estabelece IP máximo de $10 \mathrm{meq} / \mathrm{kg}$ para óleos refinados e $15 \mathrm{meq} / \mathrm{kg}$ para óleos não refinados.

Os valores de densidade encontrados foram semelhantes para os óleos tratados e não tratados, na faixa de 882 a $898 \mathrm{~kg} / \mathrm{m}^{3}$. Por outro lado, a umidade aumentou de 0,01\% (óleo centrifugado) para $0,13 \%$ para o óleo purificado, indicando que a água residual não foi removida completamente após o tratamento por degomagem. Quanto a viscosidade cinemática, houve redução do valor obtido após os tratamentos realizados, passando de 55,6 $\mathrm{mm}^{2} / \mathrm{s}$ (óleo bruto) para a faixa de $36-37 \mathrm{~mm}^{2} / \mathrm{s}$ para os demais óleos tratados e refinado.

\subsection{Análises Físico-Químicas do Biodiesel}

A caracterização dos óleos de palma bruto, tratados e refinados mostrou que os óleos não exibem condições físico-químicas ideais para síntese de biodiesel pela catálise básica homogênea. Entretanto, com intuito de avaliar a possibilidade da utilização de matériasprimas deterioradas na produção de biodiesel sem afetar a qualidade do produto obtido, foram 
realizadas reações de transesterificação empregando esses óleos como matéria-prima lipídica, pela catálise básica homogênea. Os valores para as propriedades físico-químicas dos biodieseis obtidos encontram-se na Tabela 2.

Tabela 2 - Propriedades físico-químicas do biodiesel a partir do óleo de palma bruto, centrifugado, degomado e refinado.

\begin{tabular}{|c|c|c|c|c|}
\hline Caracterização & $\begin{array}{c}\text { Biodiesel } \\
\text { Bruto }\end{array}$ & $\begin{array}{c}\text { Biodiesel } \\
\text { Centrifugado }\end{array}$ & $\begin{array}{c}\text { Biodiesel } \\
\text { Degomado }\end{array}$ & $\begin{array}{c}\text { Biodiesel } \\
\text { Refinado }\end{array}$ \\
\hline \hline Índice de Acidez $(\mathrm{mg} \mathrm{KOH} / \mathrm{g}$ óleo $)$ & $0,31 \pm 0,03$ & $0,38 \pm 0,07$ & $0,26 \pm 0,03$ & $0,07 \pm 0,03$ \\
\hline Índice de Peróxido (meq/ kg óleo) & $0,75 \pm 0,07$ & $0,33 \pm 0,04$ & $0,48 \pm 0,04$ & $0,43 \pm 0,04$ \\
\hline Densidade $\left(\mathrm{kg} / \mathrm{m}^{3}\right)$ & $906,2 \pm 21,71$ & $852,5 \pm 14,57$ & $884,30 \pm 9,47$ & $826,24 \pm 25,77$ \\
\hline Viscosidade Dinâmica $(\mathrm{cP})$ & $5,54 \pm 0,02$ & $5,79 \pm 0,01$ & $5,82 \pm 0,01$ & $3,65 \pm 0,01$ \\
\hline Viscosidade Cinemática $\left(\mathrm{mm}^{2} / \mathrm{s}\right)$ & $6,11 \pm 0,02$ & $6,79 \pm 0,01$ & $6,58 \pm 0,01$ & $4,42 \pm 0,02$ \\
\hline Umidade $(\%)$ & $2,55 \pm 2,03$ & $2,48 \pm 0,25$ & $1,87 \pm 0,80$ & $3,28 \pm 1,04$ \\
\hline
\end{tabular}

Apesar da má qualidade apresentada pelas matérias-primas, verifica-se pelos dados da Tabela 2 que a análises físico-químicas das amostras de biodiesel obtidas apresentaram resultados satisfatórios. O índice de acidez obtido foi de 0,07 a $0,38 \mathrm{mg} \mathrm{KOH} / \mathrm{g}$ óleo, o que atende a especificação da Resolução ANP no 45 (2014), que estabelece que o limite máximo de acidez do biodiesel deve ser de $0,5 \mathrm{mg} \mathrm{KOH} / \mathrm{g}$ óleo. O índice de peróxido também apresentou uma drástica redução para valores de 0,33 a $0,75 \mathrm{meq} / \mathrm{kg}$ óleo, indicando que todas as amostras obtidas não apresentam deterioração oxidativa.

Com relação a densidade a $20^{\circ} \mathrm{C}$ as amostras de biodiesel encontram-se dentro das especificações da ANP (2014), que limita em 850 a $900 \mathrm{~kg} / \mathrm{m}^{3}$. Entretanto, os valores de umidade que indicam o teor de água contido nas amostras variaram entre 1,87 a 3,28\%, considerados elevados para os padrões na norma que estabelece o limite de $0,02 \%$. Os altos teores de água obtidos revelam que o processo de secagem não foi eficiente para remover a água residual proveniente da etapa de purificação.

A viscosidade pode ser usada como um parâmetro para o controle da reação de transesterificação através da redução acentuada da viscosidade da matéria-prima. Verifica-se que, em comparação aos óleos tratados e não tratados, as amostras de biodiesel apresentaram uma redução acentuada da viscosidade (Tabela 2) sendo o menor valor obtido para o biodiesel proveniente do óleo refinado $\left(4,42 \mathrm{~mm}^{2} / \mathrm{s}\right)$ e os demais variando entre 6,11 a $6,79 \mathrm{~mm}^{2} / \mathrm{s}$. Esses valores estão bem próximos ao estipulado pela norma ANP que é de $3-6$ mm²/s.

\subsection{Espectroscopia FTIR do óleo e do biodiesel}

Para avaliar qualitativamente as amostras dos óleos antes e após o tratamento e as amostras de biodiesel obtidas, a análise de FTIR foi realizada e está ilustrada na Figura 1(a,b). Em ambos os casos, observa-se a ocorrência de bandas de absorção características em 3000$2840 \mathrm{~cm}-1$ correspondentes a deformação axial de grupos metil $(\mathrm{C}-\mathrm{H})$ e em $1760 \mathrm{~cm}^{-1}$ correspondentes a deformação axial da carbonila $(\mathrm{C}=\mathrm{O})$. Comparando os espectros verifica-se que nos espectros das amostras de biodiesel (Figura 1b) houve a inserção de uma banda característica de grupos ésteres provenientes de álcool primário $(\mathrm{O}-\mathrm{C}-\mathrm{C}) \mathrm{em} 1031 \mathrm{~cm}^{-1}$, indicando a conversão dos óleos em ésteres etílicos (Silverstein, 1998). 
Figura 1 - Espectros dos (a) óleos de palma (bruto, centrifugado, degomado e refinado) e das (b) respectivas amostras de biodiesel.
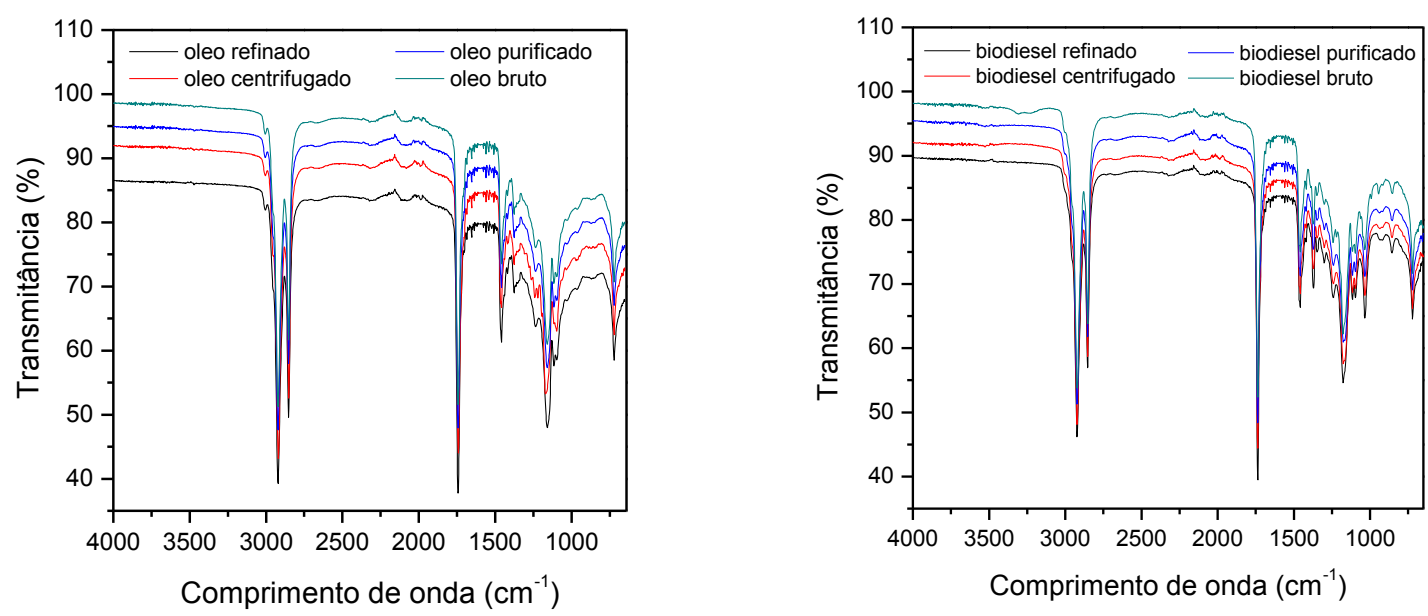

\section{CONCLUSÃO}

Tendo em vista a significativa redução de viscosidade e dos índices de acidez e peróxido dos produtos obtidos da transesterificação dos óleos tratados e não tratados, constatou-se a viabilidade da produção de biodiesel pela catálise homogênea convencional a partir de matérias-primas lipídicas não refinadas empregando etanol como agente acilante.

\section{AGRADECIMENTOS}

Os autores agradecem o apoio financeiro concedido pela FAPEMIG.

\section{REFERÊNCIAS}

ANP - Agência Nacional de Petróleo, Gás Natural e Biocombustíveis. Resolução $n^{\circ} 45$, de 25.8.2014 - DOU 26.8.2014.

ANVISA - Agência Nacional de Vigilância Sanitária. Disponível em: <http://www.anvisa.gov.br>. Acesso em: 12 março 2017.

INSTITUTO ADOLFO LUTZ. Métodos Físico-Químicos para análises de alimentos. São Paulo: Instituto Adolfo Lutz, 2008.

KURNIA, J. C.; JANGAM, S. V.; AKHTAR, S.; SASMITO, A. P.; MUJUMDAR, A. S. Advances in biofuel production from oil palm and palm oil processing wastes: A review. Biofuel Res. J., v. 9, p. 332-346, 2016.

SAJJADI, B.; RAMAN, A. A. A.; ARANDIYA, H. A comprehensive review on properties of edible and non-edible vegetable oil-based biodiesel: Composition, specifications and prediction models. Renewable Sustainable Energy Rev., v. 63, p. 62-92, 2016.

SILVERSTEIN, R.M.; WEBSTER, F. X. Spectrometric identification of organic compounds, 6th ed. New York: Wiley, 1998. 